\title{
Video Based Instructions Meningkatkan Praktik Kebersihan Diri Saat Menstruasi Pada Siswi Disabilitas Intelektual
}

\author{
Wa Ode Diana Harisa ${ }^{1}$, Endang Sri Wahyuni ${ }^{2 *}$ \\ ${ }^{1}$ Rumah Sakit Umum Daerah Wakatobi, ${ }^{2}$ Jurusan Okupasi Terapi, Poltekkes Kemenkes Surakarta \\ *Email: endangsriwahyuni84@gmail.com
}

\begin{abstract}
Backgrounds: Intellectual Disability students must be able to master the practice of personal hygiene during menstruation skills. However, to teach this skill to them is not easy. They need certain methods to learn these skills to get effective results. Video-Based Instruction is one method to teach these skills. This study aims to determine whether there is an effect of Video-Based Instruction on the practice of personal hygiene during menstruation on Intellectual Disability students. Methods: This is quantitative research with pre-experimental type and one group pretest-posttest design. The data collection tool is a "personal hygiene" questionnaire. The data analysis method uses a paired sample t-test with the help of SPSS version 25. This research conducted at SLB Negeri 3 Central Jakarta with a total sample is 20 respondents selected by the purposive sampling technique. Results: Most respondents were 14 years old (20\%), 7th grade (30\%), get menarche at 12 and 13 years (25\%). The mean score for the practice of personal hygiene during menstruation pre-test is 41.30 and post-test is 53.20. Paired sample t-test results showed that sig. (2-tailed) $<0.001$. Conclusion: The results showed that it received Ha, which means that there is an effect of Video-Based Instruction on the practice of personal hygiene during menstruation on Intellectual Disabilities students. The results also showed that there are mean score differences of the pre-test and post-test results, which is an increase in the mean score of the post-test results by 11,90.
\end{abstract}

Keywords: intellectual disability, menstruation, self-hygiene, video based instructions

\section{PENDAHULUAN}

Menstruasi merupakan salah satu peristiwa penting dalam kehidupan yang akan dialami oleh setiap perempuan. Peristiwa penting tersebut menandakan bahwa mereka sudah memasuki masa pubertas dan akan menjadi seorang wanita. Setiap perempuan yang sudah mendapatkan menstruasi harus tahu bagaimana melakukan perawatan menstruasi khususnya praktik kebersihan diri saat menstruasi. Perawatan diri saat menstruasi dilakukan agar terhindar dari berbagai penyakit karena saat menstruasi resiko terkena penyakit khususnya penyakit kesehatan reproduksi lebih tinggi (Pythagoras 2017; Sinaga et al., 2017).

Farakhiyah, Raharjo, dan Apsari (2018) menulis bahwa berdasarkan pemaparan data dari Kementerian Sosial RI pada tahun 2017, diketahui bahwa jumlah kaum difabel atau penyandang disabilitas di Indonesia mencapai 3,11\%, atau sebesar 6,7 juta jiwa. Data dari Kementerian Kesehatan Indonesia diketahui bahwa jumlah kaum difabel menunjukkan jumlah yang lebih besar, yaitu $6 \%$ dari total populasi penduduk Indonesia. Dari beberapa literatur yang membahas mengenai disabilitas intelektual, tidak ada data pasti yang menyebutkan mengenai jumlah siswi penyandang disabilitas intelektual yang sudah mengalami menstruasi.

Praktik kebersihan diri saat menstruasi perlu diajarkan kepada setiap perempuan terlebih lagi perempuan yang mengalami disabilitas intelektual. Mereka mengalami hambatan dan kesulitan dalam melakukan berbagai tugas kehidupan termasuk dalam area activity of daily living, terutama ketika melakukan 
perawatan diri khususnya dalam menjaga kebersihan diri saat menstruasi. Kondisi tersebut diperparah dengan adanya anggapan dari orang tua mereka bahwa mereka tidak bisa melakukan hal tersebut, sehingga mereka selalu dibantu dan menjadikannya tidak mandiri.

Diperlukan metode khusus yang memiliki tujuan untuk meningkatkan kemandirian mereka terutama dalam melakukan praktik kebersihan diri saat menstruasi. Salah satu metode pengajaran yang populer dan efektif adalah pengajaran berbasis video atau VideoBased Instruction. Metode ini digunakan untuk mengembangkan keterampilan akademik, keterampilan hidup fungsional sehari-hari, dan keterampilan sosial kepada individu dengan Disabilitas Intelektual (Park, Bouck, and Duenas, 2019).

Beberapa penelitian mengenai pengaruh Video-Based Instructions terhadap kemampuan individu dengan Disabilitas Intelektual dalam melakukan tugas keseharian diantaranya adalah penelitian yang dilakukan pada tahun 2018 oleh Ariyanti \& Royanto mengenai efektivitas metode intervensi social story dan video modeling dalam meningkatkan keterampilan perawatan diri selama menstruasi pada remaja dengan Disabilitas Intelektual. Penelitian yang dilakukan oleh Susilowati, Rustiyaningsih, dan Hartini pada tahun 2018 yang meneliti tentang pengaruh Video Modeling Method terhadap keterampilan berpakaian pada anak dengan Disabilitas Intelektual. Penelitian yang dilakukan oleh Mechling \& O'Brien tahun 2010 mengenai efektivitas Computer-Based Video Instruction untuk melatih 3 individu dengan disabilitas intelektual dalam menggunakan sarana transportasi umum.
Perbedaan penelitian ini dengan sebelumnya yaitu menerapkan Video Based Instructions terhadap kemampuan praktik kebersihan diri saat menstruasi pada siswi disabilitas intelektual, yang telah disusun dalam sebuah modul oleh peneliti. Video Based Instructions ini terdiri dari teknik video prompting dengan menggunakan self modeling, teknik simultaneous video modeling dengan mengunakan point of view, dan teknik power point.

Kemandirian praktik kebersihan diri saat mensturasi pada beberapa siswi dengan Disabilitas Intelektual di SLBN 3 Jakarta Pusat tidaklah sama. Mereka mengalami kesulitan dalam penggunaan pembalut dan atau cara membersihkan pembalut. Penelitian ini dilakukan dengan tujuan untuk mengetahui seberapa besar pengaruh Video-Based Instructions terhadap praktik kebersihan diri pada siswi Disabilitas Intelektual saat mengalami menstruasi.

\section{METODE PENELITIAN}

Penelitian ini menggunakan pendekatan kuantitatif jenis pre eksperimental dengan one group pretestposttest design. Adapun populasi pada penelitian ini adalah semua siswi dengan Disabilitas Intelektual yang sudah mengalami menstruasi di Sekolah Luar Biasa Negeri 3 Jakarta Pusat. Sampel penelitian berjumlah 20 siswi, yang diambil berdasarkan purposive sampling dengan kriteria sampel yaitu tidak memiliki gangguan sensori dan atau motorik, memahami instruksi sederhana, tidak dalam perawatan medis yang bertujuan untuk menghentikan atau menggangu siklus menstruasi dan, bukan siswi dengan disabilitas ganda.

Pada penelitian ini, Video Based 
Intruction dilakukan sebanyak 19 kali intervensi selama 2 bulan dalam kurun waktu 9 September - 31 Oktober 2019 dengan pelaksanaan penelitian 3 kali seminggu. Penelitian ini dilakukan pada siswi disabilitas intelektual yang bersedia menjadi subjek penelitian dan telah mendapatkan persetujuan dari pihak orang tua dan pihak sekolah. Variabel terikat dalam penelitian ini adalah praktik kebersihan diri saat menstruasi. Variabel bebas adalah pemberian Video Based Instructions. Teknik pengumpulan data berasal dari dokumentasi data kesiswaan dan pengisian kuesioner. Pengisian kuesioner diberikan sebelum dan sesudah pemberian intervensi Video Based Instructions yang terdapat pada modul Video Based Instructions untuk melatih praktik kebersihan diri saat menstruasi pada siswi Disabilitas Intelektual. Uji normalitas data yang digunakan adalah uji Shapiro-Wilk dengan analisis data menggunakan paired sample t-test.

\section{HASIL PENELITIAN}

Kakteristik sampel dijelaskan berdasarkan umur, kelas, dan usia menarke.

Tabel 1. Umur Sampel

\begin{tabular}{ccc}
\hline Umur & Fruekuensi & Presentasi $(\%)$ \\
\hline 12 & 1 & 5 \\
13 & 2 & 10 \\
14 & 4 & 20 \\
15 & 2 & 10 \\
16 & 1 & 5 \\
17 & 2 & 10 \\
18 & 2 & 10 \\
19 & 3 & 15 \\
20 & 2 & 10 \\
21 & 1 & 5 \\
\hline Total & $\mathbf{2 0}$ & $\mathbf{1 0 0}$ \\
\hline
\end{tabular}

Mayoritas sampel berumur 14 tahun (5\%) dan usia tertua 21 tahun (5\%). (20\%) yang mana usia termuda 12 tahun

Tabel 2. Kelas Pendidikan Sampel

\begin{tabular}{cccc}
\hline \multicolumn{2}{c}{ Karakteristik } & \multirow{2}{*}{ Fruekuensi } & \multirow{2}{*}{ Presentasi (\%) } \\
\cline { 1 - 2 } Kelas & Umur & & 30 \\
7 & $12,13,13,14,14,14$ & 3 & 15 \\
8 & $14,16.17$ & 3 & 15 \\
9 & $15,15,19$ & 3 & 15 \\
10 & $17,18,20$ & 4 & 20 \\
11 & $18,19,19,20$ & 1 & 5 \\
12 & 21 & $\mathbf{1 0 0}$ & Total \\
\hline Total & $\mathbf{2 0}$ & $(30 \%)$ & .
\end{tabular}

Sampel mayoritas duduk di kelas 7 (30\%) dengan rentang usia 12-14 tahun 
Tabel 3. Usia Menarke Sampel

\begin{tabular}{crc}
\hline Usia Menarke (Tahun) & Fruekuensi & Presentasi \\
\hline 10 & 3 & 15 \\
11 & 4 & 20 \\
12 & 5 & 25 \\
13 & 5 & 25 \\
14 & 3 & 15 \\
\hline Total \\
Mayoritas telah mendapatkan & mendapat menarke pada usia 10 tahun \\
menarke saat berusia 12 tahun (25\%) dan & $(15 \%)$ sedangkan sampel yang mendapat \\
13 tahun (25\%), sampel yang sudah & menarke di usia 14 tahun (15\%).
\end{tabular}

Tabel 4. Rentang Usia Sampel Saat Penelitian dengan Usia Menarke

\begin{tabular}{ccc}
\hline $\begin{array}{c}\text { Rentang Usia Sampel Saat Penelitian } \\
\text { dengan Usia Menarke (Tahun) }\end{array}$ & Frekuensi & Presentase (\%) \\
\hline 0 & 2 & 10 \\
1 & 1 & 5 \\
3 & 6 & 30 \\
4 & 2 & 10 \\
5 & 2 & 10 \\
6 & 3 & 15 \\
7 & 1 & 5 \\
8 & 2 & 10 \\
9 & 1 & $\mathbf{1 0 0}$ \\
\hline Total & $\mathbf{2 0}$ & \\
\hline Rentang usia sampel saat penelitian & di tahun yang sama dengan saat penelitian \\
dengan usia menarke selama 3 tahun & dilakukan, dan 5\% memiliki rentang \\
(30\%), 10\% baru mendapatkan menarke & waktu 9 tahun.
\end{tabular}

Tabel 5. Praktik Kebersihan Diri Siswi dengan Disabilitas Intelektual Saat Menstruasi Sebelum dan Sesudah Pemberian Intervensi

\begin{tabular}{cccccc}
\hline $\begin{array}{l}\text { Praktik Kebersihan } \\
\text { Diri Saat Mestruasi }\end{array}$ & N & Min-Max & Mean & Modus & SD \\
\hline Pre-test & 20 & $34-52$ & 41,30 & 40 & 4,49 \\
Post-tes & 20 & $43-62$ & 53,20 & $54 \& 58$ & 4,92 \\
\hline Hasil nilai rata-rata & pre-tes & praktik & 41,30 dan nilai rata-rata post-test $53,20$. \\
kebersihan diri & saat menstruasi & adalah
\end{tabular}


Tabel 6. Praktik Kebersihan Diri Saat Menstruasi Responden Sebelum dan Sesudah Intervensi Berdasarkan Klasifikasi Usia

\begin{tabular}{cccc}
\hline \multirow{2}{*}{$\begin{array}{c}\text { Praktik Kebersihan Diri Saat } \\
\text { Menstruasi }\end{array}$} & $\begin{array}{c}\text { Remaja awal } \\
(\mathbf{1 2 - 1 6} \text { tahun })\end{array}$ & $\begin{array}{c}\text { Remaja akhir } \\
(\mathbf{1 7 - 2 5} \text { tahun) }\end{array}$ & Delta \\
\cline { 2 - 3 } Mean pre-test & 41,00 & 41,60 & 0,60 \\
Mean post-test & 53,10 & 53,30 & 0,20 \\
\hline
\end{tabular}

Pada Tabel 6 menunjukkan adanya daripada remaja awal, masing-masing selisih nilai rata-rata antara hasil pre-test sebesar 0,60 dan 0,20. dan post-test remaja akhir lebih besar

Tabel 7. Deskripsi Nilai Rata-Rata Pre-Test dan Post-Test Praktik Kebersihan Diri Saat Menstruasi Berdasarkan Tingkat Pendidikan Sampel

\begin{tabular}{clrc}
\hline \multirow{2}{*}{ Praktik Kebersihan Diri Saat Menstruasi } & \multicolumn{2}{c}{ Tingkat Pendidikan } & \multirow{2}{*}{ Delta } \\
\cline { 2 - 3 } & SMP & SMA & \\
\hline Mean pre-test & 41,00 & 41,86 & 0,86 \\
Mean post-test & 52,92 & 53,71 & 0,79 \\
\hline Adapun selisih nilai rata-rata antara & \multicolumn{2}{c}{ lebih besar daripada SMP, adalah 0,86 dan } \\
pre-test dan post-test sampel tingkat SMA & \multicolumn{2}{l}{} &
\end{tabular}

Tabel 8. Deskripsi Nilai Rata-Rata Pre-Test dan Post-Test Praktik Kebersihan Diri Saat Menstruasi Berdasarkan Rentang Jarak Usia Saat Penelitian dan Usia Menarke Repsonden

\begin{tabular}{cccc}
\hline \multirow{2}{*}{$\begin{array}{l}\text { Praktik Kebersihan Diri Saat } \\
\text { Menstruasi }\end{array}$} & \multicolumn{3}{c}{ Rentang Jarak Usia Saat } \\
& Penelitian dan Usia Menarke & Delta \\
\cline { 2 - 4 } & 0-4 tahun & $\mathbf{5 - 9}$ tahun & \\
\hline Mean pre-test & 40,73 & 42,00 & 1,27 \\
Mean post-test & 53,09 & 53,33 & 0,24 \\
\hline
\end{tabular}

Selisih nilai rata-rata rentang usia tahun lebih besar daripada 0-4 tahun yaitu saat penelitian dengan usia menarke pre- 1,27 dan 0,24.

test dan post-test siswi pada kelompok 5-9

Tabel 9. Hasil Uji Paired Sampel T-Test

\begin{tabular}{lccccc}
\hline $\begin{array}{l}\text { Praktik Kebersihan Diri } \\
\text { Saat Menstruasi }\end{array}$ & N & Mean + sd & $\begin{array}{c}\text { Perbedaan } \\
\text { mean + sd }\end{array}$ & IK95\% & $\begin{array}{c}\text { Sig. } \\
(\mathbf{2} \text { tailed })\end{array}$ \\
\hline $\begin{array}{l}\text { Pre-test } \\
\text { Post-test }\end{array}$ & 20 & $41,30+4,49$ & $11,90+3,32$ & $13,45-$ & $<0,001$ \\
\hline
\end{tabular}

Hasil uji hipotesis menggunakan uji telah dilakukan, menunjukkan bahwa usia paired sampel t-test adalah 0,001 yang sampel berada pada rentang 10-14 tahun. artinya ada peningkatan hasil rata-rata Hal ini sesuai dengan data (UNESCO, nilai pre-test dan post-test sebesar 11,90. 2012) bahwa usia 10-15 tahun adalah usia

\section{PEMBAHASAN}

Berdasarkan hasil penelitian yang dimulainya masa pubertas dan pubertas pada anak perempuan salah satunya ditandai dengan menstruasi pertama kali 
atau disebut menarke/menarche. Hartman (2014) menyatakan bahwa usia rata-rata perempuan mengalami menarke yaitu antara 12-13 tahun, namun tidak menutup kemungkinan menarke dapat terjadi pada usia 9 tahun atau 17 tahun.

Hasil penelitian ini menunjukkan hal yang sama dengan penelitian yang telah dilakukan oleh Pythagoras tahun 2017. Agiwahyuanto pada tahun 2018, dan Nugraheni (2018). Masing-masing reponden penelitian mereka berusia 14 tahun dan telah mendapatkan menarke pada usia 12 tahun dan 13 tahun.

Mayoritas responden pada penelitian yang dilakukan oleh Indah (2012) duduk di kelas 8 dan pada penelitian (Maulidia et al., 2018) berada pada jenjang Sekolah Dasar. Hal ini menunjukkan bahwa karakteristik responden berdasarkan kelas/tingkat pendidikan berbeda-beda pada penelitian sejenis karena kurikulum pendidikan anak Disabilitas dan anak tanpa Disabilitas berbeda, sehingga wajar apabila di usia 18 tahun seorang siswi Disabilitas masih berada pada tingkat SMP dan usia 21 tahun masih berada pada tingkat SMU (Maulidia et al., 2018). Sebagian besar perempuan dengan Disabilitas Intelektual mencapai menarke dan mengalami menstruasi pada usia yang sama dengan teman sebayanya (Nurkhairulnisa et al., 2018).

Hasil nilai rata-rata pre-test praktik kebersihan diri saat menstruasi pada penelitian adalah 41,30 dan nilai rata-rata post-test adalah 53,20. Hasil tersebut menunjukkan bahwa menstruasi yang disertai dengan informasi dan pengetahuan yang diperoleh melalui pendidikan formal maupun non formal dapat memberikan pengaruh yang baik sehingga dapat menghasilkan perubahan sekaligus peningkatan perilaku. Hal ini didukung dengan tulisan Notoatmodjo (2012) yang menyatakan bahwa lingkungan dan pengalaman juga akan mempengaruhi kemampuan praktik seseorang.

Senada dengan penelitian Ersoy, Tekin-Iftar, and Kircaali-Iftar (2009), yang menyatakan bahwa kemampuan keterampilan perawatan menstruasi pada anak dengan disabilitas intelektual mengalami peningkatan setelah diberikan intervensi berupa Antecedent Prompt. Hasil penelitian Mutiara, Santoso, dan Irfannudin (2018) juga menunjukkan bahwa pada kelompok yang diberikan perlakukan berupa praktik personal hygiene menunjukkan adanya peningkatan kemampuan praktik pada personal hygiene-nya jika dibandingkan dengan kelompok yang tidak diberi perlakuan.

Demikian juga nilai rata-rata posttest praktik kebersihan diri saat menstruasi pada kelompok usia remaja akhir lebih tinggi dibandingkan pada remaja awal yaitu sebesar 0,20. Tingkat SMA lebih tinggi dibandingkan pada tingkat SMP yaitu sebesar 0,79 , dan pada rentang jarak usia sekarang (saat dilakukan penelitian) dan usia menarke 5-9 lebih tinggi dibandingkan dengan responden yang rentang jarak usia sekarang (saat penelitian) dan usia menarke 0-4 tahun yaitu sebesar 0,24.

Hasil tersebut membuktikan bahwa praktik dipengaruhi oleh berbagai faktor seperti usia, pengetahuan, dan pengalaman (Hastuti, Dewi, \& Pramana 2019). Tingkat pendidikan berpengaruh pada penambahan ilmu dan pengetahuan seseorang sehingga dapat disimpulkan bahwa semakin tinggi tingkat pendidikan seseorang maka orang tersebut akan semakin mudah untuk menerima informasi dan sebaliknya, seseorang yang 
memiliki tingkat pendidikan yang rendah, maka pemahaman dan penjelasan mengenai informasi akan sulit untuk diingat dan diterima (Notoatmodjo, 2012).

Pernyataan Notoatmodjo senada dengan Pythagoras (2017) bahwa pengalaman dapat menambah informasi dalam bentuk pengetahuan dan keahlian dalam pengambilan suatu keputusan dan tindakan. Pengalaman ialah suatu kegiatan yang digunakan untuk membentuk pengetahuan seseorang yang akan memunculkan sebuah perilaku apabila dilakukan secara berulang. Jadi, semakin lama siswi mengalami menstruasi maka semakin banyak pula pengetahuan dan informasi serta peristiwa yang didapatkan oleh siswi tersebut. Pengalaman yang baik meningkatan pengetahuan. Hasil penelitian ini sejalan dengan penelitian Bujawati, Raodhah, and Indriyanti, tahun 2017. Pada penelitiannya diketahui bahwa mayoritas responden $(71 \%)$ yang memiliki pengetahuan yang cukup tentang menstruasi juga mempunyai praktik kebersihan diri yang dinilai cukup $(85,7 \%)$.

Hasil dari penelitian yang telah dilakukan, menunjukkan bahwa terdapat perbedaan nilai rata-rata hasil praktik kebersihan diri saat menstruasi saat sebelum dan sesudah diberikan intervensi Video-Based Instructions sebesar 11,90 (p $<0,001)$. Dengan demikian, didapatkan bahwa nilai $p$ value $<0,05$, maka dapat ditarik kesimpulan $\mathrm{Ha}$ diterima yang berarti terdapat pengaruh Video Based Instructions terhadap praktik kebersihan diri saat menstruasi siswi Disabilitas Intelektual. Hal ini senada dengan penelitian (Ariyanti \& Royanto 2018) yang menunjukkan terdapat peningkatan keterampilan melakukan praktik kebersihan diri saat menstruasi setelah menerima intervensi berupa video modeling dan social story sebanyak 6 kali pertemuan pada seorang anak dengan disabilitas intelektual. Hasil penelitian lainnya adalah penelitian Susilowati, Rustiyaningsih dan Hartini (2018), dari hasil penelitiannya tersebut juga menunjukkan adanya perbedaan signifikan antara kelompok eksperimen dan kelompok kontrol $(\mathrm{p}=0,041)$ dengan menggunakan video modeling dan Self Development Program sebagai media intervensinya.

Implikasi klinis dari penelitian ini adalah bahwa Video-Based Instructions sangat penting diberikan kepada siswi disabilitas intelektual agar dapat membantu siswi disabilitas intelektual dalam melakukan praktik kebersihan diri saat menstruasi sehingga mereka lebih dapat mandiri.

\section{KESIMPULAN DAN SARAN}

Kesimpulan pada penelitian ini yaitu intervensi Video Based Instructions memiliki pengaruh yang signifikan terhadap kemampuan praktik kebersihan diri saat menstruasi pada siswi dengan disabililtas intelektual di SLB Negeri 3 Jakarta Pusat. Kemampuan praktik dapat dipengaruhi oleh usia, pengetahuan, tingkat pendidikan, dan pengalaman.

Saran yang dapat diberikan: memberikan edukasi tentang kebersihan diri saat menstruasi sejak beranjak usia pubertas, melibatkan berbagai pihak dalam pemberikan pelatihan praktik, dan menggunakan metode yang mudah dalam memberikan pembelajaran praktik.

\section{DAFTAR RUJUKAN}

Agiwahyuanto, F. (2018). Gambaran Tingkat Pengetahuan Praktik Vulva Hygiene Saat Menstruasi Pada 
Siswa Kelas Viii Smp Negeri 25 Semarang Tahun Pelajaran 20172018. Jurnal Visikes, 17(1), 127135.

Ariyanti, T. D., \& Royanto, L. R. M. (2018). The Effectiveness of Social Stories and Video Modeling in Improving Self-Care Skills in Female Adolescents with Mild Intellectual Disabilities during Menstrual Periods. Advance in Social Science, Education and Humanities Research (ASSEHR), 135(ICIAP 2017), 189-199. https://doi.org/10.2991/iciap-

17.2018.16

Bujawati, E., Raodhah, S., \& Indriyanti, I. (2017). Faktor-Faktor Yang Berhubungan dengan Personal Hygiene Selama Menstruasi pada Santriwati di Pesantren Babul Khaer Kabupaten Bulukumba, Provinsi Sulawesi Selatan Tahun 2016. HIGIENE: Jurnal Kesehatan Lingkungan, 3(1), 1-9.

Ersoy, G., Tekin-Iftar, E., \& Kircaali-Iftar, G. (2009). Effects of antecedent prompt and test procedure on teaching simulated menstrual care skills to females with developmental disabilities. Education and Training in Developmental Disabilities, 44(1), 54-66.

Farakhiyah, R., Raharjo, S. T., \& Apsari, N. C. (2018). Perilaku Seksual Remaja Dengan Disabilitas Mental. Share: Social Work Journal, 8(1), 114.

https://doi.org/10.24198/share.v8i1. 18122
Hartman, D. (2014). Sexuality and Relationship Education "Teach Puberty." In Sexuality and Relationship Education (pp. 83-91). Jessica Kingsley Publishers.

Hastuti, Dewi, R. K., \& Pramana, R. P. (2019). Studi Kasus tentang Manajemen Kebersihan Menstruasi ( MKM ) Siswa SD dan SMP Pentingnya Fasilitas WASH di Sekolah. 12.

Indah, I. L. (2012). Gambaran Pengetahuan Remaja Putri Tentang Perineal Hygiene di SMPIT As Salam Pasar Minggu. In Universitas Indonesia. Universitas Indonesia.

Maulidia, W., Ernawaty, J., Rahmalia, S., \& Damanik, H. (2018). Hubungan Dukungan Keluarga terhadap Kemandirian Anak Tunagrahita dalam Mengahadapi Menarke. JOM FKp., 5(2), 429-438.

Mechling, Linda; O’Brien, E. (2010). Computer-Based Video Instruction to Teach Students with Intellectual Disabilities to Use Public Bus Transportation. Education and Training in Autism and Developmental Disabilities, 45(2), p230-241.

Mutiara, N., Santoso, B., \& Irfannudin. (2018). Pengaruh penyuluhan personal hygiene terhadap tingkat pengetahuan tentang menstruasi dan praktik personal hygiene pada siswi Kelas IX di SMP Negeri 24 Palembang dan SMP Negeri 45 Palembang. Majalah Kedokteran Sriwijaya, 50(2), 64-73. 
Notoatmodjo, S. (2012). Kesehatan Masyarakat Ilmu \& Seni. In Rineka Cipta. Rineka Cipta.

Nugraheni, D. Y. (2018). Pengaruh Peer Group Education Terhadap Perilaku Personal Hygiene Saat Menstruasi Pada Siswi Di SMP Negeri 2 Dagangan Kabupaten Madiun. In Journal of Chemical Information and Modeling. Bhakti Husada Mulia.

Nurkhairulnisa, A. I., Chew, K. T., Zainudin, A. A., Lim, P. S., Shafiee, M. N., Kampan, N., Wan Ismail, W. S., Grover, S., \& Nur Azurah, A. G. (2018). Management of Menstrual Disorder in Adolescent Girls with Intellectual Disabilities: A Blessing or a Curse? Obstetrics and Gynecology International, 2018. https://doi.org/10.1155/2018/979568 1

Park, J., Bouck, E., \& Duenas, A. (2019). The Effect of Video Modeling and Video Prompting Interventions on Individuals With Intellectual Disability: A Systematic Literature Review. Journal of Special Education Technology, 34(1), 3-16. https://doi.org/10.1177/0162643418 780464

Pythagoras, K. C. (2017). Personal Hygiene Remaja Putri Ketika Menstruasi. Jurnal Promkes, 5(1), 12-24. https://doi.org/10.1007/9783-319-93701-4_44

Sinaga, E., Saribanin, N., Suprihatin, Sa'adah, N., Salamah, U., Murti, Y. A., Trisnamiati, A., \& Lorita, S.
(2017). Manajemen Kesehatan Menstruasi. Universitas Nasional. http://ppi.unas.ac.id/wpcontent/uploads/2017/06/BukuManajemen-Kesehatan-MenstruasiOke.pdf

Susilowati, L., Rustiyaningsih, A., \& Hartini, S. (2018). Effect of Self Development Program and Training Using Video Modeling Method on Dressing Skills in Children With Intellectual Disability. Belitung Nursing Journal, 4(4), 420-427. https://doi.org/10.33546/bnj.331

UNESCO. (2012). Buku Suplemen Bimbingan Teknis Kesehatan Reproduksi Pubertas. BKKBN. https://adoc.pub/queue/2615169804 6211290.html 